\title{
N-Acetylglutamate Content in Liver and Gut of Normal and Fasted Mice, Normal Human Livers, and Livers of Individuals with Carbamyl Phosphate Synthetase or Ornithine Transcarbamylase Deficiency
}

\author{
MENDEL TUCHMAN AND ROBERT A. HOLZKNECHT \\ Division of Metabolism, Departments of Pediatrics and Laboratory Medicine and Pathology, University of \\ Minnesota, Minneapolis, Minnesota 55455
}

\begin{abstract}
N-acetylglutamate (NAG) content was measured in homogenates of liver and small intestine obtained from normal and 24-h starved syngeneic mice. Subsequently, NAG was determined in normal, and in carbamyl phosphate synthetase I and ornithine transcarbamylase enzyme-deficient human liver tissue homogenates. The method used in this study, which is direct and highly specific, used anion exchange extraction, gas chromatographic separation, and mass spectrometric detection and quantitation. Hepatic NAG content in the fed animals was $94.8 \pm 19.8 \mathrm{nmol} / \mathrm{g}$ tissue or $602.5 \pm 168.4 \mathrm{nmol} / \mathrm{g}$ protein (mean $\pm \mathrm{SD}, n=5$ ), whereas it was much lower in the fasted mice $(49.4 \pm 13.0 \mathrm{nmol} / \mathrm{g}$ tissue or $330.1 \pm 113.9$ $\mathrm{nmol} / \mathrm{g}$ protein, mean $\pm \mathrm{SD}, \boldsymbol{n}=5$ ). The magnitude of the difference was much smaller for intestinal NAG content, $19.8 \pm 5.4 \mathrm{nmol} / \mathrm{g}$ tissue or $205.3 \pm 70.3 \mathrm{nmol} / \mathrm{g}$ protein (mean $\pm \mathrm{SD}, n=5$ ) in the fed mice and $14.2 \pm 4.3 \mathrm{nmol} /$ $\mathrm{g}$ tissue or $168.1 \pm 80.8 \mathrm{nmol} / \mathrm{g}$ protein (mean $\pm \mathrm{SD}, n=$ 5 ) in the fasted mice. The concentrations of hepatic NAG in normal human livers (controls) ranged from 19.3 to 67.1 $\mathrm{nmol} / \mathrm{g}$ tissue $(41.6 \pm 19.3$, mean $\pm \mathrm{SD}, n=5)$ or from 193 to $764.3 \mathrm{nmol} / \mathrm{g}$ of protein $(437.5 \pm 233.4$, mean \pm $\mathrm{SD}, n=5$ ). In three patients with apparently complete carbamyl phosphate synthetase I or ornithine transcarbamylase deficiency, hepatic NAG levels were lower than controls $(2.2-12.8 \mathrm{nmol} / \mathrm{g}$ tissue $42.3-140.7 \mathrm{nmol} / \mathrm{g}$ protein), two patients with ornithine transcarbamylase deficiency had levels similar to the controls and one patient with carbamyl phosphate synthetase I deficiency had elevated levels $(98.4 \mathrm{nmol} / \mathrm{g}$ tissue, $1185.5 \mathrm{nmol} / \mathrm{g}$ protein). The livers of two patients with cirrhosis and hyperammonemia contained amounts of NAG within the range of normal livers. The marked variability in tissue NAG concentrations in various nutritional and metabolic conditions favors the hypothesis that NAG plays a role in the regulation of urea synthesis. Hepatic NAG levels are markedly reduced in some but not all patients with defects in urea cycle enzymes. (Pediatr Res 27: 408-412, 1990)
\end{abstract}

\section{Abbreviations}

NAG, N-acetylglutamate

NAGS, $\mathrm{N}$-acetylglutamate synthase

Received July 28, 1989; accepted December 8, 1989

Reprint requests: Mendel Tuchman, M.D., Department of Pediatrics, University of Minnesota, Box 400, Mayo Memorial Building, 420 Delaware Street S.E., Minneapolis MN 55455.

Supported in part by Grant NO1-DK-6-2274 from the NIH and by grants from the Minnesota Medical Foundation.
CPS I, carbamyl phosphate synthetase I

OTC, ornithine transcarbamylase

GC-MS, gas chromatography-mass spectrometry

MSD, mass selective detector

SIM, selected ion monitoring

TMS, trimethylsilyl

In 1953, Grisolia and Cohen (1) discovered that a derivative of L-glutamic acid enhanced the biosynthesis of L-citrulline by preparation of mammalian liver. This naturally occurring compound was isolated and identified as NAG, which is the cofactor of mitochondrial CPS I, the first enzyme of the urea cycle in ureotelic animals (2). NAG is an allosteric activator of this enzyme (3) altering its conformation (4). Ammonia, ATP, and bicarbonate anion are substrates for CPS I, an enzyme catalyzing the formation of carbamyl phosphate according to the following reaction:

$$
\begin{aligned}
2 \mathrm{ATP}+\mathrm{HCO}_{3}+\mathrm{NH}_{3} \frac{\mathrm{CPSI}-\mathrm{NAG}}{+} \gg 2 \mathrm{ADP} \\
+\mathrm{H}_{2} \mathrm{~N} \mathrm{COO} \mathrm{PO}_{3}^{--}+\mathrm{H}_{3} \mathrm{PO}_{4} .
\end{aligned}
$$

Without NAG, the enzymatic activity of CPS I in vitro is undetectable. NAG is synthesized in the mitochondria from acetyl-CoA and L-glutamate by an enzymatic reaction catalyzed by NAGS (5). The enzymatic activity of rat and human NAGS in the presence of saturating concentrations of substrates can be doubled in the presence of $\mathrm{L}$-arginine $(6,7)$.

The dependence of CPS I activity on availability of NAG, and reports on correlations between hepatic NAG content and ingestion of proteins or ammonia in animals $(5,8)$ prompted investigations on the possible role of hepatic NAG content in the control of urea synthesis. Research on the biology of NAG has been hampered by the lack of specific chemical methodologies for measurement of NAG. The biologic assay for the measurement of NAG exploiting its effect on the activity of CPS I may be highly inaccurate (9). Moreover, the chemical methods used did not estimate NAG directly, but rather used quantitation of glutamate after extraction and enzymatic hydrolysis of NAG to glutamate, as an indirect measurement of NAG $(9,10)$.

Virtually all studies on hepatic NAG were performed on animals. Little is known about NAG content in normal human liver and no studies have been reported on NAG in livers of patients with defects in urea cycle enzymes. Two patients with NAGS deficiency causing hyperammonemia have been reported (11-13); however, their liver NAG content was not reported. 
This study was undertaken to investigate NAG content of hepatic and intestinal tissue obtained from normal and fasted syngeneic mice. Furthermore, normal liver tissue and tissue obtained from patients with CPS I and OTC deficiency were also studied. A new, specific and sensitive method using GC-MS determination was developed for this study. This method, and the information obtained in this investigation would be applicable for investigating the physiology of NAG, as well as primary NAG deficiency (inherited NAGS deficiency) and secondary NAG deficiency in patients with hyperammonemia.

\section{MATERIALS AND METHODS}

Materials. N-acetyl-L-glutamic acid (NAG), L-glutamic acid, and DEAE Sephadex, 40-120 $\mu \mathrm{m}$ particle size, were purchased from Sigma Chemical Co., St. Louis, MO. L-[U- ${ }^{14}$ C]glutamic acid $(285 \mathrm{mCi} / \mathrm{mmol})$ was purchased from Amersham Corp., Arlington Heights, IL. N,O bis-(trimethylsilyl) trifluoroacetamide $+10 \%$ trimethylchlorosilane (Regisil RC-3) was purchased from Regis Chemical Company, Morton Grove, IL.

Animals. Ten 7-mo-old female syngeneic CD2F1 mice were included in this study. The animals were fed ad libitum until 24 $\mathrm{h}$ before harvesting the tissues at which time a group of five mice was placed on a fast allowing only water intake. The remaining five mice continued to be fed ad libitum. All 10 mice were killed by cervical dislocation at about the same time and pieces of their livers and small intestines were rapidly removed and were flash frozen in liquid nitrogen. The tissues were stored at $-80^{\circ} \mathrm{C}$ until analysis.

Human tissue. Frozen normal human liver tissue used in this study was obtained through the University of Minnesota "Liver tissue procurement and distribution system" by NIH contract. The livers were frozen immediately after harvesting in liquid nitrogen or were maintained for less than $8 \mathrm{~h}$ in a buffered solution (Wisconsin solution), after which sections of the liver were flash frozen in liquid nitrogen and stored at $-80^{\circ} \mathrm{C}$ until analysis. Liver tissue samples from six patients with hyperammonemia caused by inherited deficiencies in the activities of CPS I or OTC enzymes were obtained surgically or shortly after death, frozen in liquid nitrogen, and stored at $-80^{\circ} \mathrm{C}$. The specific enzymatic diagnosis was established by radiochromatographic assays as described before (14). Two patients had complete CPS I deficiency, three had complete OTC deficiency, and one had partial OTC deficiency.

Preparation of liver homogenates. Sections of frozen liver or gut were weighed and about $100 \mathrm{mg}$ (wet wt) of tissue was homogenized in $1 \mathrm{~mL}$ of deionized water on ice by a Polytron apparatus (Brinkmann Instruments, Westbury, NY) using two 20-s cycles with a 60-s interval. Protein concentration of liver homogenate was measured by the BCA method (15). The protein was immediately precipitated with $1 \mathrm{~mL}$ ice cold $30 \%$ trichloroacetic acid.

Extraction of $N A G$. The supernatant of the mixtures was separated from the precipitate by centrifugation at $500 \times g$ for 2 min, the trichloroacetic acid was quickly removed by extracting three times with $5 \mathrm{~mL}$ of diethyl ether. The sample's $\mathrm{pH}$ was adjusted to 7.5-8.0 with $1 \% \mathrm{KOH}$ solution and hepatic NAG was then extracted using a small anion exchange gravity column containing a volume of $2 \mathrm{~mL}$ DEAE Sephadex charged with 0.5 $\mathrm{M}$ pyridinium formate. The samples were placed on the columns, and were washed with $5 \mathrm{~mL}$ of deionized water to eliminate basic and neutral compounds and then with $5 \mathrm{~mL}$ of $0.1 \mathrm{M}$ pyridinium formate to eliminate glutamic acid as well as other weaker acids. NAG was then eluted with $0.3 \mathrm{M}$ pyridinium formate solution. After freeze drying of the eluate, the dry residue was derivatized with $100 \mu \mathrm{L}$ BSTFA/TMCS $10: 1$ (vol/vol) at $60^{\circ} \mathrm{C}$ for $20 \mathrm{~min}$ to form trimethylsilyl derivative of NAG.

$G C-M S$ determination of $N A G$. Two $\mu \mathrm{L}$ of the derivatized extract were injected into the gas chromatograph (5890 gas chromatograph, Hewlett Packard, Avondale, PA) and were sep- arated on a cross-linked $0.2 \mathrm{~mm}$ OD, $25 \mathrm{~m}$ long, $5 \%$ phenylmethylsilicone capillary column with a film thickness of $0.52 \mu$ (Ultra 2, Hewlett Packard). The oven's temperature program started at $100^{\circ} \mathrm{C}$, increasing by $20^{\circ} \mathrm{C} / \mathrm{min}$ up to $270^{\circ} \mathrm{C}$. Injection port and transfer line temperatures were 250 and $280^{\circ} \mathrm{C}$, respectively. Split injection mode was used with a split ratio of $1: 50$. Flow rate of the carrier gas, helium, was $1 \mathrm{~mL} / \mathrm{min}$ and its linear velocity was $35 \mathrm{~cm} / \mathrm{s}$. Detection was by mass spectrum detector (5971 quadrupole MSD, Hewlett Packard) equipped with $70 \mathrm{eV}$ electron impact ion source by selected ion monitoring mode, monitoring $\mathrm{m} / \mathrm{z} 216$ and $\mathrm{m} / \mathrm{z} 318$ ions. Dwell time was $20 \mathrm{~ms}$ and resolution was 0.5 atomic mass unit. Quantitation was performed by external standardization according to the NAG peak areas recorded by the MSD compared to known amounts of extracted standards. Results of tissue NAG content were expressed as nmol/g of wet wt and as nmol/g of protein.

Determination of liver arginine. Liver arginine concentrations in the supernates of human liver samples were determined by ion exchange chromatography using an automatic amino acid analyzer (Beckman Instruments, Fullerton, CA) using a method identical to the one used for plasma samples as per Beckman Instrument's protocol.

\section{RESULTS}

The anion exchange extraction used in this study efficiently separated L-glutamic acid from NAG. Elimination of tissue glutamic acid before derivatization was preferable to prevent any possibility of chemical formation of NAG from tissue glutamate and acetyl-CoA during derivatization. The binding of NAG to the stationary phase of the column is stronger than that of $\mathrm{L}$ glutamate. Figure 1 shows the elution sequence of both compounds. All the glutamic acid loaded onto the column was eluted by $0.1 \mathrm{M}$ pyridinium formate solution, whereas none of the NAG appeared in that eluate. The great majority of NAG was eluted by $0.2 \mathrm{M}$ pyridinium formate. The extraction efficiency (recovery) of NAG using this method was $85-90 \%$ and the reproducibility of NAG determination in liver tissue was $\pm 10 \%$.

NAG was efficiently separated from other acids by the capillary column and detected by the MSD. Figure 2 shows an SIM chromatogram obtained for NAG after injection of a derivatized intestine extract into the gas chromatograph and its detection by the MSD. Using selected ion monitoring mode of detection enabled quantitation of as low as $3.5 \mathrm{ng}$ of NAG. This limit of detection is equivalent to less than $1 \mathrm{nmol} / \mathrm{g}$ of tissue NAG content when a total of $50 \mathrm{mg}$ of normal liver tissue is used in the assay. The MSD detector response for NAG was not completely linear (Fig. 3), the results were therefore calculated based on the detector's response curve for various amounts of extracted standards.

The results obtained from the animal studies are summarized in Table 1. Liver content of NAG in fed mice was $94.8 \pm 19.8$ $\mathrm{nmol} / \mathrm{g}$ tissue or $602.5 \pm 168.4 \mathrm{nmol} / \mathrm{g}$ protein $($ mean $\pm \mathrm{SD}$ ), almost twice as high as the levels in 24 -h fasted mice (49.4 \pm 13.0 or $330 \pm 113.9)$ with a significant statistical difference $(p$ $0.01)$. Mean intestinal NAG levels were also higher in the fed mice $(19.8 \pm 5.4 \mathrm{nmol} / \mathrm{g}$ tissue or $205.3 \pm 70.3 \mathrm{nmol} / \mathrm{g}$ protein $)$ compared to the fasted mice $(14.2 \pm 4.3$ or $168.1 \pm 80.8)$, however, the differences were not statistically significant. Some reduction of organ wt during fasting probably occurred, which may decrease the wt/cell ratio and protein/cell ratio. Therefore, NAG levels obtained in the fasted animals probably represent maximum values.

Table 2 summarizes the levels of NAG and arginine obtained from frozen human normal livers, livers with cirrhosis, and livers with CPS I or OTC deficiency. NAG levels in structural and functional normal human liver tissue obtained from five individuals ranged from 19.3 to $67.1 \mathrm{nmol} / \mathrm{g}(41.6 \pm 19.3$, mean $\pm \mathrm{SD}$, $n=5$ ). Adjusted to liver protein content the normal range was from 193 to $764.3 \mathrm{nmol} / \mathrm{g}$ protein $(437.5 \pm 233.4$, mean $\pm \mathrm{SD}$, 


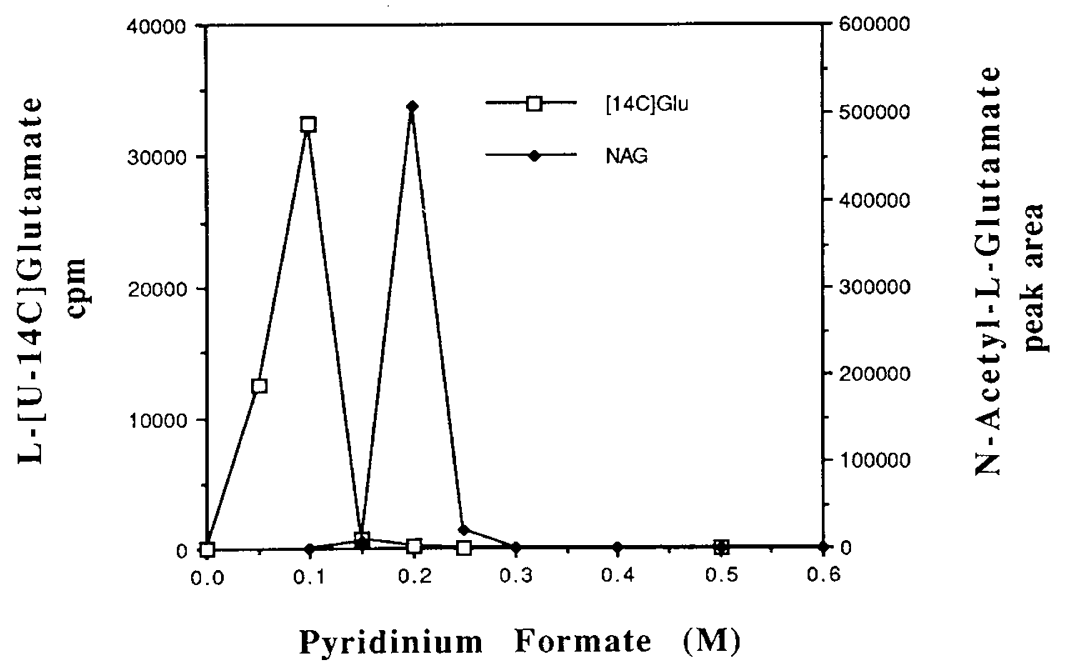

Fig. 1. Plot of the elution patterns of L-glutamic acid and $\mathrm{N}$-acetylglutamate by the anion exchange method used in this study. The ion exchange resin was DEAE-Sephadex and the elution acid pyridinium formate.

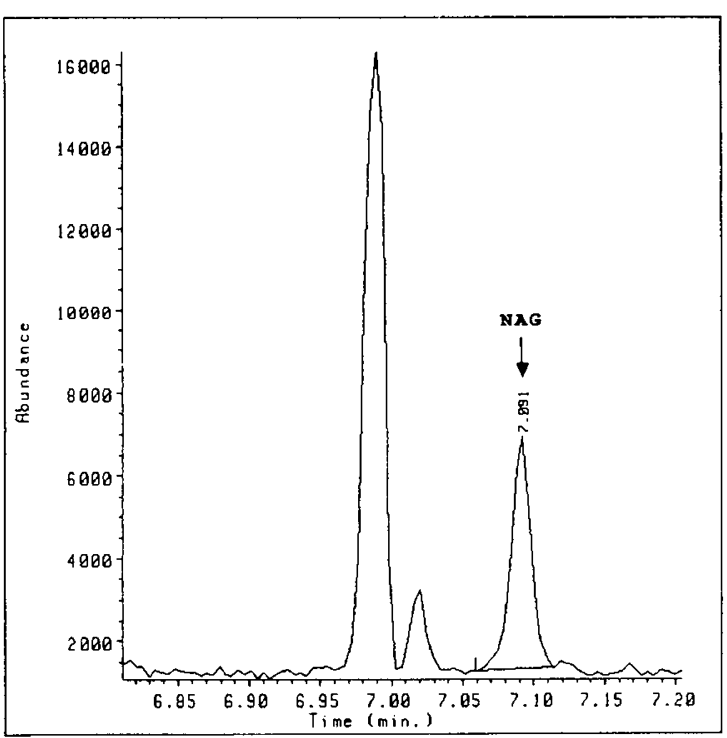

Fig. 2. Selected ion monitoring chromatogram of the sum of the $\mathrm{m} / \mathrm{z} 216$ plus $\mathrm{m} / \mathrm{z} 318$ ion current obtained after extraction of NAG from $100 \mathrm{mg}$ of mouse intestine, trimethylsilyl derivatization, and injection into the gas chromatograph-mass spectrometer. The peak eluting at $7.09 \mathrm{~min}$ is that of NAG, whereas the earlier peaks are unknown compounds of intestinal origin.

$n=5)$. The lowest level of hepatic NAG (2.2 nmol/g tissue or $42.3 \mathrm{nmol} / \mathrm{g}$ protein) among patients with urea cycle enzyme defects was measured in the liver of patient CPS I 1 . This patient was in poor nutritional status due to frequent recurrent hyperammonemia episodes. He underwent liver transplantation and prior to removal of his liver was treated for several hours with i.v. administration of sodium benzoate and phenylacetate. Patient CPS I 2 had the highest level of hepatic NAG $(98.4 \mathrm{nmol} /$ $\mathrm{g}$ tissue or $1185.5 \mathrm{nmol} / \mathrm{g}$ protein) among all human livers that were studied. This CPS I-deficient patient died at the age of $4 \mathrm{~d}$ from hyperammonemic coma. His liver was removed $30 \mathrm{~min}$ after death. Patient OTC 1 had markedly reduced hepatic NAG levels. He developed hyperammonemic coma at the age of $4 \mathrm{~d}$ and was treated with sodium benzoate and arginine. His hyperammonemia continued to rise despite the treatment and he died at the age of $1 \mathrm{wk}$. His liver tissue was obtained $1 \mathrm{~h}$ post mortem. Patient OTC 2 also had low hepatic NAG levels. He developed hyperammonemia and died at $4 \mathrm{~d}$ of age. He was treated with arginine. His liver tissue was obtained within $30 \mathrm{~min}$ of death. Patient OTC 3 had lower than normal levels of NAG. He developed hyperammonemia at $2 \mathrm{~d}$ of life and died at the age of $10 \mathrm{~d}$. Patient OTC 4 who had partial OTC deficiency was asymptomatic until 6 y of age when he developed hyperammonemic coma and died within $2 \mathrm{~d}$. His liver tissue was harvested $30 \mathrm{~min}$ after his death. His hepatic NAG level was normal. No correlation was found between the variability of NAG content and the hepatic levels of arginine. Moreover, liver CPS 1 with the lowest NAG content contained higher amounts of arginine compared to most other livers.

\section{DISCUSSION}

The exact mechanism(s) regulating urea synthesis is still unknown. CPS I, the first enzyme in the urea cycle is the only enzyme of that pathway that requires an organic cofactor (NAG) for its catalytic function. Logically, NAG became a target for studies of the regulation of urea synthesis. Shigesada and Tatibana (5) have shown that NAG content in mouse liver increased from 15 to $40 \mathrm{nmol} / \mathrm{g}$ tissue in response to increasing dietary protein content from 0 to $60 \%$ (5). Meijer and Hensgens (16) presented evidence that mitochondrial NAG concentrations play an important role in regulation of urea synthesis. Lund and Wiggins (9) have questioned this conclusion on the biologic role of NAG, claiming that the biologic method (effect on CPS I activity) for measuring NAG is highly inaccurate. This method was used in the studies of Meijer and Hensgens (16) where the role of NAG was determined. Using a chemical method, Lund and Wiggins (9) found higher values of hepatic NAG than those reported in previous studies. Based on those values they postulated that mitochondrial NAG concentrations are much higher than the activation constant of NAG for CPS I and assumed therefore that NAG is unlikely to be a regulator of urea synthesis.

None of the methods used in the above studies was direct. The chemical methods relied on the measurement of glutamate formed after deacylation of extracted NAG. The method used in this study is accurate and direct. Although our method is less sensitive than the HPLC method described by Alonso and Rubio (10), their method also measured NAG indirectly after deacylation to form glutamate. The chemical indirect method may be hampered by variable enzymatic activity of the aminoacylase used to convert NAG to glutamate (17). The tissue levels measured by our method in the fed animals agree with those published by Lund and Wiggins (9) for rat liver (9) and are twice as high as those reported by Shigesada and Tatibana (5) for a different strain of mice. 


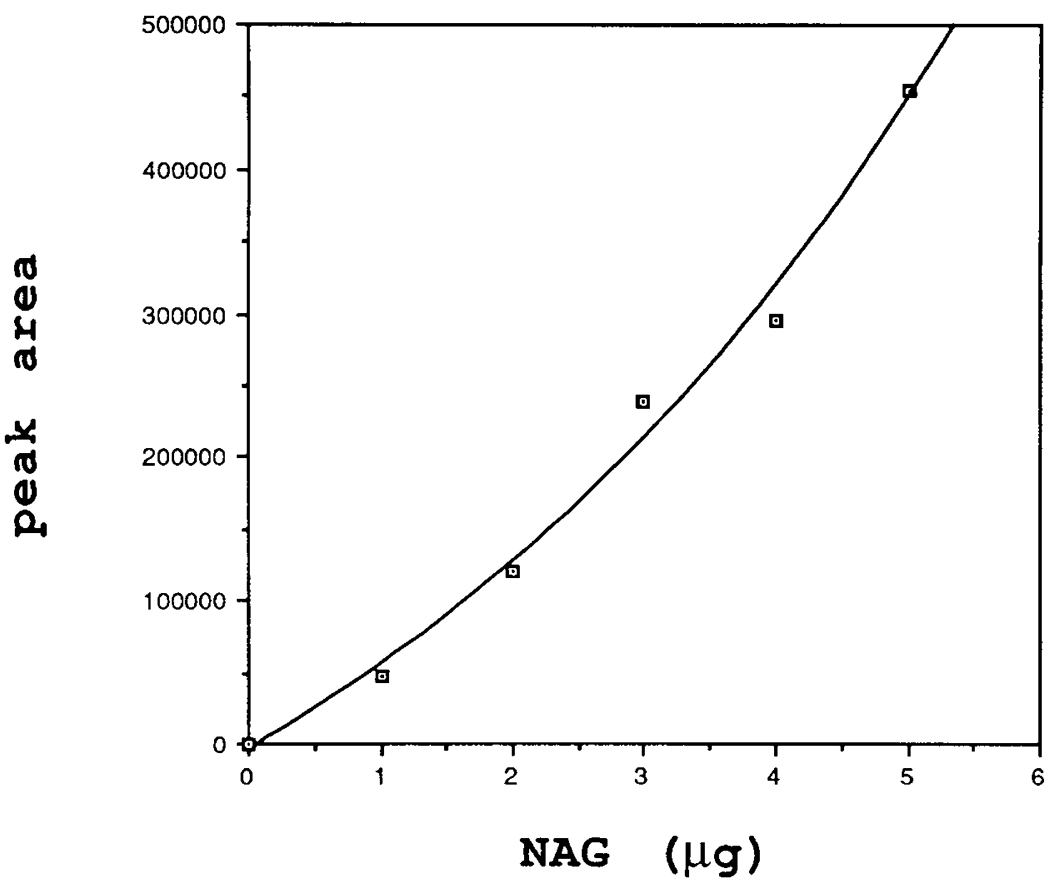

Fig. 3. Mass spectrum detector response for the sum of the $\mathrm{m} / \mathrm{z} 216$ plus $\mathrm{m} / \mathrm{z} 318$ ion current with increasing amounts of NAG in the sample. Total volume of the derivatized sample was $100 \mu \mathrm{L}$ of which $2 \mu \mathrm{L}$ were injected into the gas chromatograph-mass spectrometer.

Table 1. NAG content in liver and small intestine of fed and $24-h$ fasted mice*

\begin{tabular}{|c|c|c|c|c|}
\hline \multirow{2}{*}{ No. } & \multicolumn{2}{|c|}{ Fed $\dagger$} & \multicolumn{2}{|c|}{ Fasted $\dagger$} \\
\hline & Liver & Gut & Liver & Gut \\
\hline 1 & $82.0(471.2)$ & $27.1(241.8)$ & $41.3(244.2)$ & $18.2(236.6)$ \\
\hline 2 & $107.3(735.0)$ & $17.2(148.0)$ & $68.1(417.9)$ & $19.3(272.4)$ \\
\hline 3 & $112.3(796.7)$ & $20.2(255.3)$ & $49.3(460.7)$ & $12.7(130.7)$ \\
\hline 4 & $106.1(609.5)$ & $21.8(268.8)$ & $34.1(189.7)$ & $9.6(96.3)$ \\
\hline 5 & $66.4(400.2)$ & $12.6(112.5)$ & $54.1(337.9)$ & $11.4(104.7)$ \\
\hline \multirow[t]{2}{*}{ Mean \pm SD } & $94.8 \pm 19.8$ & $19.8 \pm 5.4$ & $49.4 \pm 13.0$ & $14.2 \pm 4.3$ \\
\hline & $(602.5 \pm 168.4)$ & $(205.3 \pm 70.3)$ & $(330.1 \pm 113.9)$ & $(168.1 \pm 80.8)$ \\
\hline
\end{tabular}

* Expressed as nmol per gram tissue and as $\mathrm{nmol} / \mathrm{g}$ protein in parentheses.

$\dagger$ Liver and intestinal tissue of five mice (nos. $1,2,3,4,5$ ) in each group were assayed.

Table 2. NAG content in sections of normal livers, cirrhotic livers of patients with hyperammonemia, and livers of patients with CPS I and OTC deficiency

\begin{tabular}{|c|c|c|c|c|c|c|c|c|}
\hline $\begin{array}{l}\text { Normal } \\
\text { livert' }\end{array}$ & $\mathrm{NAG}^{+*}$ & $\operatorname{Arg} \ddagger$ & Deficient liver§ & NAG & Arg & $\begin{array}{l}\text { Cirrhotic } \\
\text { liver } 1\end{array}$ & NAG & Arg \\
\hline 1 & $19.3(193.0)$ & $<0.1$ & CPS I 1 & $2.2(42.3)$ & 1.54 & 1 & $27.1(444.3)$ & 2.3 \\
\hline 2 & $27.2(261.5)$ & $<0.1$ & CPS I 2 & $98.4(1185.5)$ & 1.08 & 2 & $69.4(722.9)$ & 1.15 \\
\hline 3 & $40.7(395.1)$ & 0.87 & OTC 1 & $8.5(141.7)$ & $\mathrm{ND}^{* *}$ & & & \\
\hline 4 & $67.1(573.5)$ & 0.77 & OTC 2 & $18.9(230.5)$ & $<0.1$ & & & \\
\hline 5 & $53.5(764.3)$ & $<0.1$ & OTC 3 & $12.8(140.7)$ & $<0.1$ & & & \\
\hline Mean $\pm S D$ & $\begin{array}{c}41.6 \pm 19.3 \\
(437.5 \pm 233.4)\end{array}$ & & OTC 4 (partial) & $30.7(379.0)$ & $<0.1$ & & & \\
\hline
\end{tabular}

* Normal frozen liver tissue of five different individuals (nos. 1, 2, 3, 4, 5).

$\dagger$ Expressed as $\mathrm{nmol} / \mathrm{g}$ tissue and as $\mathrm{nmol} / \mathrm{g}$ protein in parentheses.

$\ddagger$ Liver arginine in $\mu \mathrm{mol} / \mathrm{g}$ protein.

$\S$ Patients with inherited defects in CPS I or OTC.

I Patients with cirrhosis due to antitrypsin deficiency or extrahepatic biliary atresia having hyperammonemia.

** Not detected.

The marked difference in NAG hepatic content between fed and starved mice may indicate that NAG plays an important role in the regulation of urea synthesis in the liver. However, a much less significant difference was found in intestinal NAG content between the fed and fasted animals. This lack of statistically significant difference may merely be due to the low number of animals tested, although the clear difference between NAG patterns in the liver and intestine indicates a dissimilarity in NAG metabolism in the two organs. No other reports on intestinal NAG levels in various nutritional conditions are known to us.

Human hepatic NAG values have not been published before. The wide range of NAG content found in the human livers assayed in this investigation did not correlate with hepatic arginine that is postulated to control NAGS activity. Our results may be explained by variable metabolic and nutritional conditions of 
the individuals before the removal of the tissues. However, NAG levels found in the patients with urea cycle enzymatic defects are of interest because most of them were out of the normal control range. The lowest NAG level was found in the liver of a CPS Ideficient patient who underwent liver transplantation. This patient had been infused with sodium benzoate and phenylacetate for several hours before the removal of his liver. These two compounds are activated in the liver by attachment of coenzyme A (18). The CoA esters of benzoate and phenylacetate could have inhibited the enzymatic activity of NAGS by competition with acetyl-CoA for the enzyme or by depleting the acetyl-CoA available for NAG synthesis as is the case in patients with propionic acidemia where coenzyme $\mathrm{A}$ is trapped as propionylCoA (19). In experimental animals, sodium benzoate potentiates the lethal effect of hyperammonemia and this effect could be prevented by L-carnitine, presumably by releasing CoA from fatty acids and making it available for other cell functions (20). These observations suggest that reduced concentrations of free mitochondrial CoA may cause a reduction in NAG synthesis.

The cause for the very high levels of hepatic NAG in patient CPS I 2 is obscure. We are currently investigating the presence and amount of CPS I cross-reactive material in both CPS I deficient livers to assess whether their NAG levels have any correlation to the amounts of the CPS I protein.

The lower than normal NAG levels in both livers of patients with complete OTC deficiency may explain the reason for intermittent absence of significant orotic aciduria in some patients with OTC deficiency (Tuchman $\mathbf{M}$, unpublished observation). NAG deficiency caused by low protein diets could cause secondary CPS I malfunction and therefore prevent the synthesis of carbamyl phosphate, the precursor of orotic acid. However, it is unclear whether the source of orotic aciduria in patients with OTC deficiency is the liver, gut, or both. Orotic acid production should be higher in rapidly dividing tissue that should favor the gut rather than the liver as the source of orotic acid in OTC patients. If this hypothesis is correct, the magnitude of orotic aciduria could depend, among other factors, on NAG concentrations in the intestinal mucosa. If liver NAG content is low also in patients with more distal blocks in the urea cycle such as citrullinemia and argininosuccinic aciduria, a secondary block in the function of CPS I may add to the severity of their hyperammonemia. These patients could be studied for the effects of carbamylglutamate (21) (stable, biologically active analog of NAG) administration on their hyperammonemia.

\section{REFERENCES}

1. Grisolia S, Cohen PP 1953 Catalytic role of glutamate derivatives in citrulline biosynthesis. J Biol Chem 204:753-757
2. Hall LM, Metzenberg RL, Cohen PP 1958 Isolation and characterization of a naturally occurring cofactor of carbamyl phosphate biosynthesis. J Biol Chem 230:1013-1021

3. Marshall M, Metzenberg RL, Cohen PP 1958 Purification of carbamyl phosphate synthetase from frog liver. J Biol Chem 233:102-105

4. Guthohrlein G, Knappe J 1968 Structure and function of carbamoylphosphate synthase. I. Transitions between two catalytically inactive forms and the active form. Eur J Biochem 7:119-127

5. Shigesada K, Tatibana M 1971 Role of acetylglutamate in ureotelism. I. Occurrence and biosynthesis of acetylglutamate in mouse rat tissues. J Biol Chem 246:5588-5595

6. Bachmann C, Krahenbuhl S, Colombo JP 1982 Purification and properties of acetyl-CoA: L-glutamate $\mathrm{N}$-acetyltransferase from human liver. Biochem $\mathrm{J}$ 205:123-127

7. Kawamoto S, Sonoda T, Ohtake A, Tatibana M 1985 Stimulatory effect of arginine on acetylglutamate synthesis in isolated mitochondria of mouse and rat liver. Biochem J 232:329-334

8. Felipo V, Minana MD, Grisolia S 1988 Long-term ingestion of ammonium increases acetylglutamate and urea levels without affecting the amount of carbamoyl-phosphate synthase. Eur J Biochem 176:567-571

9. Lund P, Wiggins D 1984 Is N-acetylglutamate a short-term regulator of urea synthesis? Biochem J 218:991-994

10. Alonso E, Rubio V 1985 Determination of N-acetyl-L-glutamate using highperformance liquid chromatography. Anal Biochem 146:252-259

11. Bachmann C, Krahenbuhl S, Colombo JP, Schubiger G, Jaggi KH, Tonz O $1981 \mathrm{~N}$-acetylglutamate synthetase deficiency: a disorder of ammonia detoxification. N Engl J Med 304:543

12. Bachmann C, Colombo JP, Jaggi K $1982 \mathrm{~N}$-acetylglutamate synthetase (NAGS) deficiency: diagnosis, clinical observations and treatment. Adv Exp Med Biol 153:39-45

13. Bachmann C, Brandis M, Weissenbarth-Riedel E, Burghard R, Colombo JP $1988 \mathrm{~N}$-acetylglutamate synthetase deficiency, a second patient. J Inherited Metab Dis 11:191-193

14. Tuchman M, Tsai MY, Holzknecht RA, Brusilow SW 1989 Carbamyl phosphate synthetase and ornithine transcarbamylase activities in enzyme deficient human liver measured by radiochromatography and correlated with outcome. Pediatr Res 26:77-82

15. Smith PK, Krohn RI, Hermanson GT, Mallia AK, Gartner FH, Provenzano MD, Fujimoto EK, Goeke NM, Olson BJ, Klenk DC 1985 Measurement of protein using bicinchoninic acid. Anal Biochem 150:76-85

16. Meijer AJ, Hensgens HESJ 1982 Ureagenesis. In: Sies H (ed) Metabolic Compartmentation. Academic Press Inc, London New York, pp 259-286

17. Cohen NS $1984 \mathrm{~N}$-acetylglutamate-independent activity of carbamyl phosphate synthetase (ammonia): implications for the kinetic assay of acetylglutamate. Arch Biochem Biophys 232:38-46

18. Webster LT, Siddiqui UA, Lucas SW, Strong JM, Mieyal JJ 1976 Identification of separate acyl-CoA: glycine and acyl-CoA: L-glutamine N-acyltransferase activities in mitochondrial fractions from liver of rhesus monkey and man. J Biol Chem 251:3352-3358

19. Rabier D, Briand P, Petit F, Kamoun P, Cathelineau L 1986 Effects of organic acids on the synthesis of citrulline by intact rat liver mitochondria. Biochimie 68:639-647

20. O'Connor JE, Costell M, Grisolia S 1987 The potentiation of ammonia toxicity by sodium benzoate is prevented by L-carnitine. Biochem Biophys Res Comm 145:817-824

21. O'Connor JE, Jorda A, Grisolia S 1985 Acute and chronic effects of carbamylglutamate on blood urea and ammonia. Eur J Pediatr 143:196-197 